\title{
Effect of nutrient and stress factors on polysaccharides synthesis in Proteus mirabilis biofilm*
}

\author{
Magdalena Moryl ${ }^{\boxplus}$, Aleksandra Kaleta ${ }^{1}$, Kacper Strzelecki ${ }^{1}$, Sylwia Różalska ${ }^{2}$ and Antoni \\ Różalski
}

'Department of Immunobiology of Bacteria, ${ }^{2}$ Department of Industrial Microbiology and Biotechnology, Faculty of Biology and Environmental Protection, University of Lodz, Łódź, Poland

\begin{abstract}
The extracellular matrix in biofilm consists of water, proteins, polysaccharides, nucleic acids and phospholipids. Synthesis of these components is influenced by many factors, e.g. environment conditions or carbon source. The aim of the study was to analyse polysaccharides levels in Proteus mirabilis biofilms after exposure to stress and nutritional conditions. Biofilms of 22 P. mirabilis strains were cultivated for 24, 48, 72 hours, 1 and 2 weeks in tryptone soya broth or in modified media containing an additional amount of nutrients (glucose, albumin) or stress factors (cefotaxime, $\mathrm{pH} \mathrm{4,} \mathrm{nutrient} \mathrm{de-}$ pletion). Proteins and total polysaccharides levels were studied by Lowry and the phenol-sulphuric acid methods, respectively. Glycoproteins levels were calculated by ELLA with the use of selected lectins (WGA and HPA). For CLSM analysis dual fluorescent staining was applied with SYTO 13 and WGA-TRITC. In optimal conditions the levels of polysaccharides were from 0 to $442 \mu \mathrm{g} / \mathrm{mg}$ of protein and differed depending on the strains and cultivation time. The agents used in this study had a significant impact on the polysaccharides synthesis in the $P$. mirabilis biofilm. Among all studied components (depending on tested methods), glucose and cefotaxime stimulated the greatest production of polysaccharides by $P$. mirabilis strains (more than a twofold increase). For most tested strains the highest amounts of sugars were detected after one week of incubation. CLSM analysis confirmed the overproduction of $\mathrm{N}$-acetyloglucosamine in biofilms after cultivation in nutrient and stress conditions, with the level $111-1134 \%$, which varied depending on the $P$. mirabilis strain and the test factor.
\end{abstract}

Key words: Proteus mirabilis, exopolysaccharides, biofilm, nutrient, stress factors

Received: 31 October, 2013; revised: 10 January, 2014; accepted: 22 January, 2014; available on-line: 19 March, 2014

\section{INTRODUCTION}

Proteus mirabilis is an opportunistic pathogen, which can be found in natural environments, e.g. soil, water, and sewage, as well as in animal intestinal tracts. These bacteria cause many different types of diseases - most frequently urinary tract infections (UTIs), especially in patients with urinary catheters (CAUTIs) Jacobsen et al., 2008). They form biofilm on a catheter surface, detected in $65-85 \%$ of CAUTIs cases (Muzzi-Bjornson \& Macera 2011). P. mirabilis synthesize a lot of virulence factors, e.g. urease. The activity of this enzyme leads to biofilm encrustation with apatite and struvite crystals, which could cause blockade of the catheter lumen and make infection persistent and difficult to treat (Stickler \& Feneley 2011). Encrusted biofilms are more resistant to antimicrobial agents, host defenses and environmental stress conditions.

The extracellular matrix (ECM) is a very important biofilm component. It consists of water (97\%) and exopolymers, which are a mixture of: polysaccharides (EPS), proteins, nucleic acids, glicoproteins and phospholipids. The average thickness of a biopolymer layer is $0.2-1.0 \mu \mathrm{m}$ (Czaczyk \& Myszka 2007). Carbohydrates found in the matrix are homo- or heteropolysaccharides composed of 2-8 types of sugars. The majority of microorganisms synthesize neutral sugars (e.g hexoses), possessing an anionic charge (uronic acids, pyruvic acids) or containing phosphate or sulphate groups. The molecular weight of the sugars usually ranges between $0.5-2$ $\times 10^{6} \mathrm{kDa}$ (Sutherland 2001, Czaczyk \& Myszka 2007). Electrostatic and hydrogen bonds are often involved in polysaccharides linking to bacterial cells, another posibility is binding by lipids and glycerol.

Bacterial EPS play an important role in biofilm development, e.g. they participate in the adhesion process, where they intensify the cells binding to solid surfaces. EPS are also neccessary in biofilm matriculation, they increase the distance between cells, which stabilises the biofilm structure. EPS participate also in transport of the nutrients to the bacterial cells (Sutherland 2001, Nwodo et al., 2012). EPS functions include also regulation of biofilm dispersal processes and contribution to bacterial communication (quorum sensing). However, the most important is their protective role. They constitute a mechanical barrier which protects bacterial cells against the harmful environmental influence of e.g antimicrobials, UV radiation or macroorganism immune system agents (phagocytosis, opsonization). EPS compounds can also react with antimicrobial agents, bind them and prevent their atachment to receptors on bacterial cells. EPS is also a virulence factor — strains which produce EPS are

e-mail: magdabar@biol.uni.lodz.pl

*Presented at the 3-rd Workshop on Microbiology "MIKROBIOT 2013" in Łódź, Poland.

Abbreviations: ABTS 2,2'-azino-bis(3-ethylbenzothiazoline-6-sulphonic acid), CAUTI catheter associated urinary tract infection, CLSM confocal laser scanning microscope, CTX cefotaxime, DMSO dimethyl sulfoxide, ECM extracellular matrix, ELLA enzyme linked lectinosorbent assay, EPS extracellular polysaccharides, GalNAc $\mathrm{N}$-acetylgalactosamine, GIcNAc N-acetylglucosamine, HPA Helix pomatia agglutinin, PBS phosphate buffered saline, TRITC tetramethylrhodamine-5-(and-6)-isothiocyanate, TSB tryptone soya broth, UTI urinary tract infection, WGA wheat germ agglutinin 
more pathogenic than EPS non producing strains (Starkey et al., 2004).

The composition and quantity of exopolymers depend on microorganisms species, the stage of biofilm matriculation, as well as environmental conditions such as carbon source and balance between the following elements: nitrogen, potassium and phosphorus. The temperature and $\mathrm{pH}$ also influence the EPS synthesis and structure (Vu et al., 2009).

The knowledge of the EPS structure could be extended by developing new biofilm eradication methods, based on matrix destruction. Therefore, it is extremely important to characterize the P. mirabilis EPS. Chemical structures of polysaccharides in the $P$. mirabilis matrix have not been discovered, but generally these compounds could be similar to O-specific chains of the lipopolysaccharide (Różalski et al., 2007). The purpose of our study was the analysis of differences in the levels of polysaccharides in $P$. mirabilis biofilms after exposure to stress and nutritional conditions. The first step was the determination of the polysaccharides and proteins levels in P. mirabilis biofilm in optimal medium (TSB). The second stage involved a study of the effect of nutrient deficiencies, acidic $\mathrm{pH}$, and the presence of an antibiotic (cefotaxime), albumin or an additional amount of glucose in culture medium on polysaccharides synthesis.

\section{MATERIAL AND METHODS}

Bacterial strains. 22 P. mirabilis strains were obtained from biofilms on urinary catheters collected from longterm catheterized patients. Catheterization lasted from a few months to a few years, however, each catheter was replaced every two weeks. The strains were stored at $-80^{\circ} \mathrm{C}$ in tryptone soya broth (TSB, BTL Corp.) and in $10 \%$ dimethyl sulfoxide (DMSO), and cultivated on tryptone soya agar (TSA, BTL Corp.). Bacteria were incubated for $24 \mathrm{~h}$ at $37^{\circ} \mathrm{C}$. For experiments bacteria were grown in TSB broth for $24 \mathrm{~h}, 37^{\circ} \mathrm{C}$.

Biofilm cultivation. $P$. mirabilis biofilms were cultivated in flat-bottomed polystyrene 96-well plates in TSB or media modified with the addition of glucose $(500 \mathrm{mM})$, albumin $(1.54 \mathrm{mg} / \mathrm{ml})$, cefotaxime — CTX (a subinhibitory concentration - $32 \mu \mathrm{g} / \mathrm{ml})$, TSB tenfold diluted with distilled water, TSB pH 4. $100 \mu$ l volumes of particular media, inoculated with P. mirabilis $\left(10^{7}\right.$ cells per $\mathrm{ml})$ were transferred into polystyrene plates. The plates were incubated for $24 \mathrm{~h}, 48 \mathrm{~h}, 72 \mathrm{~h}$, one or two weeks at $37^{\circ} \mathrm{C}$ (fresh media were supplied every $72 \mathrm{~h}$ ). After cultivation biofilms were washed twice with distilled water to remove unbound bacterial cells. Next, levels of polysaccharides and proteins were determined.

Proteins and polysaccharides determination. Concentrations of obtained proteins were measured using the method described by Lowry et al. (1951) with bovine serum albumin as a standard. The amount of total carbohydrate was determined using the phenol-sulphuric acid method described by Dubois et al. (1956) with glucose as a standard.

An enzyme-linked lectinosorbent assay (ELLA) was used to determine the glycoproteins levels in $P$. mirabilis biofilms. Wheat germ agglutinin (WGA) was applied to detect $\beta(1 \rightarrow 4)-\mathrm{N}$-acetyl-D-glucosamine residues and Helix pomatia agglutinin (HPA) to detect $\alpha-\mathrm{N}$ acetylgalactosamine residues were applied. $100 \mu \mathrm{l}$ of peroxidase conjugated lectins at the concentration of $1.25 \mu \mathrm{g} / \mathrm{ml}$ in PBS were overlaid on plates. After $1 \mathrm{~h}$ incubation, biofilms were five times rinsed with PBS with
0.05\% Tween 20. Next, ABTS 2,2'-azino-bis(3-ethylbenzothiazoline-6-sulphonic acid) (Sigma) was added for 15 min. and absorbance was measured at $595 \mathrm{~nm}$, on microtiter plate reader (Multiscan EX, Labsystems).

CLSM analysis. P. mirabilis biofilms were cultivated in transmission flow cells (BioSurface Technologies) for $48-72 \mathrm{~h}$ with a flow $0.5 \mathrm{ml} / \mathrm{min}$ of medium or on glass slides. After incubation, biofilms were washed with distilled water to remove planktonic bacteria. Nucleic acids were fluorescently stained with SYTO 13 (Molecular Probes) at a concentration of $50 \mu \mathrm{M}$. Biofilms were incubated for $15 \mathrm{~min}$., next the dye was washed and extracellular polysaccharides in the matrix were stained with WGA-TRITC lectin — $50 \mu \mathrm{g} / \mathrm{ml}$ (Sigma). After $30 \mathrm{~min}$. incubation, stained biofilms were rinsed to remove unbound lectins. The imaging was performed using a Pascal (Zeiss) confocal laser scanning microscope equipped with a $40 \times(0.75$ numerical aperture $)$ objective lens. The excitation wavelength was $488 \mathrm{~nm}$ and emission was 514 $\mathrm{nm}$ for SYTO 13, while for WGA-TRITC they were 543 $\mathrm{nm}$ and $620 \mathrm{~nm}$, respectively. The images analysis was performed using the AxioVision software, which allowed the quantification of EPS and bacterial cells.

Statistical analysis. Experiments were repeated at least three times. Data are presented as the mean \pm standard deviation. All statistical analyses were performed with the Statistica 10 PL software. A Mann-Whitney U test was used to compare the means ( $p$ value $\leq 0.05$ was taken as statistically significant and $\mathrm{p} \leq 0.01$ as highly statistically significant).

\section{RESULTS}

\section{The amounts of polysaccharides obtained in optimal conditions.}

P. mirabilis biofilms were cultivated in TSB medium for $24 \mathrm{~h}, 48 \mathrm{~h}, 72 \mathrm{~h}$, one or two weeks. The phenolsulphuric acid method and the Lowry method were used to examine the amounts of polysaccharides per $1 \mathrm{mg}$ of protein. The polysaccharides amounts obtained in optimal conditions ranged between 0 - and almost 442 $\mu \mathrm{g} / \mathrm{mg}$ of protein and differed depending on the strains and cultivation times (Table 1). The highest levels were measured for $P$. mirabilis strains no. 12, 34, 44, 77, 84 and the lowest for strains number 6 and 9. For most of the tested $P$. mirabilis strains the polysaccharides levels did not rise with an increasing incubation time. The highest levels of total carbohydrates were noticed after one week incubation and averaged $106.1 \mu \mathrm{g} / \mathrm{mg}$ of proteins for all tested strains.

\section{Polysaccharides levels after biofilm incubation in stress conditions}

Polysaccharides levels in control medium and after biofilm cultivation in different media supplemented with tested factors were compared. The percentage of polysaccharides overproduction in relation to control medium was calculated. The results obtained using both phenol-sulphuric acid and ELLA methods are presented in five similar diagrams — one for each factor (Fig. 1). The figures show the average results obtained after $168 \mathrm{~h}$ of cultivation. Value $100 \%$ indicates the amounts of polysaccharides equal to the controls, above this level the overproduction of these compounds could be observed.

Enrichment of the growth medium with additional nutrients led to increased synthesis of polysaccharides in 
Table 1. Amount of polysaccharides in Proteus mirabilis biofilm after cultivation in control medium [ $\mu \mathrm{g} / \mathrm{mg}$ of proteins]

\begin{tabular}{|c|c|c|c|c|c|}
\hline \multirow{2}{*}{ P. mirabilis strains } & \multicolumn{5}{|c|}{ Incubation time } \\
\hline & $24 \mathrm{~h}$ & $48 \mathrm{~h}$ & $72 \mathrm{~h}$ & 1 week & 2 weeks \\
\hline 5 & $36.9 \pm 7.4$ & $12.2 \pm 3.1$ & $16.3 \pm 5.4$ & $10.1 \pm 3.3$ & $83.1 \pm 41.5$ \\
\hline 6 & 0 & 0 & $4.3 \pm 0.4$ & 0 & $57.3 \pm 27.1$ \\
\hline 7 & 0 & $169.4 \pm 71.6$ & 0 & 0 & $164 \pm 54.4$ \\
\hline 8 & 0 & $65.7 \pm 22.8$ & $37 \pm 15.6$ & $21.9 \pm 7.1$ & $53.4 \pm 30.2$ \\
\hline 9 & 0 & 0 & $23.6 \pm 5.8$ & 0 & $62.6 \pm 35.9$ \\
\hline 11 & $30.8 \pm 8.1$ & $40.6 \pm 2.6$ & $27.9 \pm 9.1$ & 0 & $28.7 \pm 5.2$ \\
\hline 12 & $19.9 \pm 1.3$ & $107.1 \pm 10.8$ & $78.2 \pm 30.9$ & $100 \pm 22.6$ & $193.9 \pm 15.9$ \\
\hline 15 & $114.3 \pm 47.5$ & $46.4 \pm 11.6$ & $30.5 \pm 6.7$ & 0 & $99.7 \pm 18.2$ \\
\hline 20 & $22.2 \pm 5.9$ & $10.9 \pm 2.7$ & $29.9 \pm 5.4$ & $229.7 \pm 110.9$ & $142.0 \pm 18.6$ \\
\hline 24 & $35.7 \pm 10.5$ & $31.1 \pm 10.1$ & $50.2 \pm 19$ & $99 \pm 38.4$ & $132.5 \pm 29.0$ \\
\hline 31 & $54.4 \pm 11.6$ & $20.3 \pm 2.6$ & $74.3 \pm 12$ & $48.5 \pm 15$ & $127.9 \pm 34.6$ \\
\hline 32 & 0 & $47.6 \pm 14.8$ & 0 & $94.7 \pm 35.1$ & $55.6 \pm 21.8$ \\
\hline 33 & $9.5 \pm 2.2$ & $94.9 \pm 5.9$ & 0 & $301.7 \pm 97.1$ & $27.3 \pm 1.9$ \\
\hline 34 & $5.9 \pm 0.7$ & $441.8 \pm 184.5$ & 0 & 0 & $150.2 \pm 50.2$ \\
\hline 41 & 0 & $97.3 \pm 35$ & $111.9 \pm 26.9$ & $135.4 \pm 63.6$ & 0 \\
\hline 44 & $27.3 \pm 11.7$ & $17.3 \pm 4.7$ & $39 \pm 12$ & $93.3 \pm 11.6$ & $403.4 \pm 179.6$ \\
\hline 46 & $13.1 \pm 6.0$ & $145.1 \pm 46.1$ & $32.8 \pm 7.1$ & $159.5 \pm 37.5$ & $48.7 \pm 16.9$ \\
\hline 57 & $16.6 \pm 4.1$ & $38.3 \pm 5.8$ & $126.6 \pm 32.4$ & $48.1 \pm 9.3$ & $37.9 \pm 4.0$ \\
\hline 70 & $74 \pm 6.5$ & $39.3 \pm 2.8$ & 0 & $204.7 \pm 20.6$ & $119.2 \pm 17.6$ \\
\hline 71 & 0 & $28.2 \pm 6.2$ & $52.2 \pm 12.1$ & $236.7 \pm 28.1$ & $18.8 \pm 2.8$ \\
\hline 77 & 0 & $355.2 \pm 62.2$ & $78.9 \pm 18$ & $287 \pm 51.2$ & $246.1 \pm 47.1$ \\
\hline 84 & $113.2 \pm 18.8$ & $10.5 \pm 1$ & $121.4 \pm 7.6$ & $279.5 \pm 39$ & $74.9 \pm 40.3$ \\
\hline
\end{tabular}

P. mirabilis biofilm. After biofilm cultivation with a high concentration of glucose, more than a twofold increase $(234 \%)$ in polysaccharide levels was detected in the case of 14 to 16 strains (depending on the tested method) (Fig. 1A). The largest amounts of polysaccharides were detected for $P$. mirabilis strains no.: $5,12,34,41,70,77$ (an increase by $364-1775 \%$ in relation to the control, $\mathrm{p} \leq 0.01)$. In the case of strains no. $12,15,24,31,41,57$, 70 , overproduction of polysaccharides was confirmed using all studied methods. A reduction in polysaccharides levels, after the biofilm growth in medium supplemented with glucose, was observed for three strains: 6, 9 and 20 (about 39, 61, 64\%, respectively). The addition of the second nutrient factor - albumin to culture medium also resulted in increased synthesis of polysaccharides in P. mirabilis biofilm. Total carbohydrate levels in the case of 20 strains were more than threefold higher (335\%) compared to those obtained after biofilm cultivation in TSB (Fig. 1B). N-acetyloglucosamine and N-acetylogalactosamine amounts were similar to those detected in control medium, $150 \%$ overproduction for 13 strains and $110 \%$ for 8 strains were detected, respectively. In the case of $14 \mathrm{P}$. mirabilis strains the $\mathrm{N}$-acetylogalactosamine residues levels were lower (by about 44\%) compared to the control. A bacterial culture in adverse conditions, after the application of stress factors, led to the stimulation of the sugars synthesis for most of the tested strains. After biofilm cultivation in medium with the reduced nutrient content, an increase in the amounts of polysaccharides was observed (depending on the method) in the case of 10 to 18 P. mirabilis strains (Fig. 1C).
The average level of polysaccharides was about 1.25 times higher compared to the control medium. A considerable increase in the $\mathrm{N}$-acetyloglucosamine synthesis was noticed for strains no. 44 and 71 (about 232 fold and 15 fold, respectively; $\mathrm{p} \leq 0.01)$. Interestingly, this factor inhibited the synthesis of polysaccharides in the case of some strains, e.g. $\mathrm{N}$-acetylogalactosamine levels were reduced by approximately $48 \%$ for $12 \mathrm{P}$. mirabilis strains. Total carbohydrate levels were lower (at about 100-5\%) for 10 strains. The $\mathrm{N}$-acetyloglucosamine levels were reduced by an average $37 \%$ in the case of only 4 strains. Acidic $\mathrm{pH}$ also influenced the polysacharide synthesis of studied strains. 15 to $17 \mathrm{P}$. mirabilis strains exposed to this agent produced higher amounts of glicoproteins and total saccharides. In these conditions a twofold increase in the polysacharides levels was confirmed using all tested methods (Fig. 1D). The addition of subminimal doses of cefotaxime to growth medium stimulated polysaccharides synhtesis (depending on the method) in the case of 12 to 15 strains — about 1.5-2.7 higher levels compared to those obtained in control media were detected (Fig. 1E).

Considering all cultivation times and all bacterial strains, it was concluded that the studied factors had a significant influence on polysaccharide synthesis. Slightly different results were obtained depending on the method used (Fig. 2). The $\mathrm{N}$-actetylglucosamine level in biofilms was higher after a shorter incubation period and it significantly decreased after $72 \mathrm{~h}$ of incubation - values statistically significant at $\mathrm{p} \leq 0.01$ (Fig. 2A). The overproduction of GlcNAc residues was the most effective in 

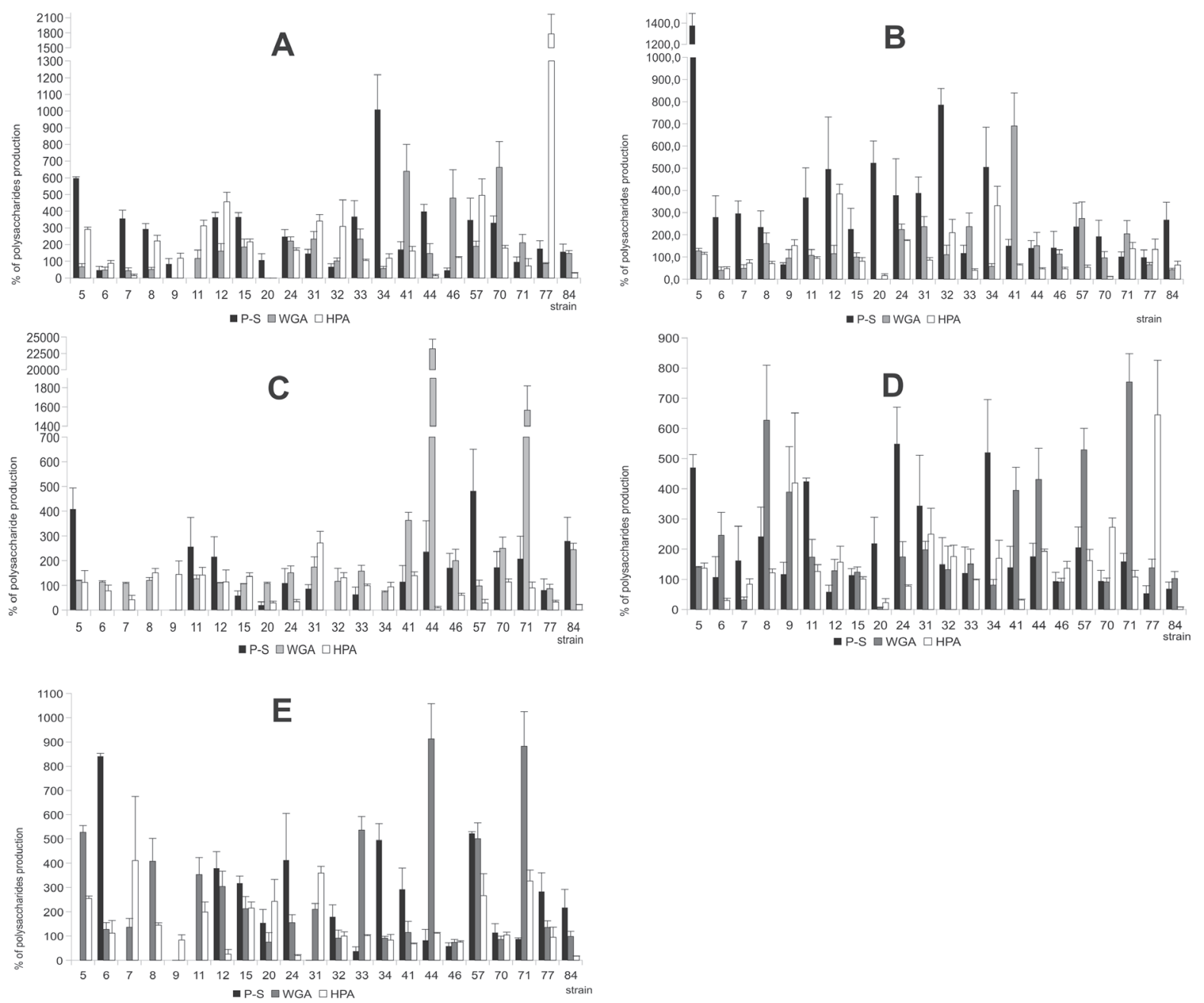

Figure 1. Effects of tested factors (A - glucose - $500 \mathrm{mM}$; B - albumin - $1.54 \mathrm{mg} / \mathrm{ml}$; C - nutrient depletion, D - pH 4, E - cefotaxime $-32 \mu \mathrm{g} / \mathrm{ml}$ ) on polysaccharides synthesis in $22 P$. mirabilis biofilms cultivated for $168 \mathrm{~h}$.

Results were obtained using three methods: P-S — phenol-sulphuric acid, WGA — ELLA with WGA lectin, HPA — ELLA with HPA lectin and presented as a percentage of the saccharides amount in relation to the control (100\%). Results above $200 \%$ were statistically significant $\mathrm{p} \leq 0.05$; results above $300 \%$ were highly statistically significant $p \leq 0.01$.

media containing cefotaxime. The lowest polysaccharides production (similar to the control) was noticed in media with albumin above $48 \mathrm{~h}$ of cultivation.

$\mathrm{N}$-acetylgalactosamine levels rose with an increasing incubation time (especially to $168 \mathrm{~h}$ ) (Fig. 2B). The overproduction of GalNAc residues was observed above $72 \mathrm{~h}$ of incubation. A similar trend was detected for all studied factors.
Total carbohydrates levels were similar in all cultivation times and they were about 2-3-fold higher compared to the control conditions (Fig. 2C). The lowest levels of saccharides were observed after biofilm cultivation in media with nutrient depletion, the values of these compounds were slighty higher than those obtained in optimal medium.

Table 2. Polysaccharides production analyzed by CLSM (\% of polysaccharide overproduction in relation to control - 100\%)

\begin{tabular}{llll}
\hline \multirow{2}{*}{ Factor } & & \multicolumn{2}{l}{ Polysaccharide production (\%) } \\
\cline { 2 - 3 } & & P. mirabilis 41 & P. mirabilis 70 \\
\hline \multirow{3}{*}{ Nutrients factors } & Control TSB medium & 100 & 100 \\
& Glucose & $474.2 \pm 17.7^{*}$ & $204.9 \pm 18.6^{*}$ \\
\hline \multirow{3}{*}{ Stress factors } & Albumin & $451.5 \pm 25.7^{*}$ & $110.6 \pm 36.5$ \\
& Nutrient depletion & $469.3 \pm 5.8^{*}$ & $1134.5 \pm 156.2^{*}$ \\
\hline
\end{tabular}

*values statistically significant at $p \leq 0.05$ 
A

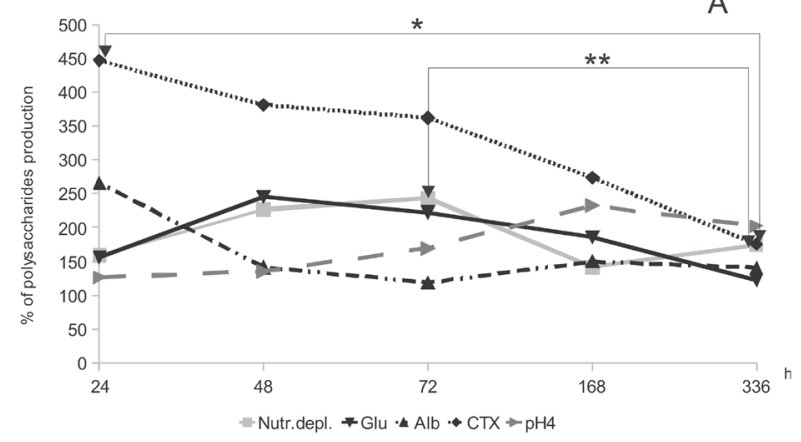

C

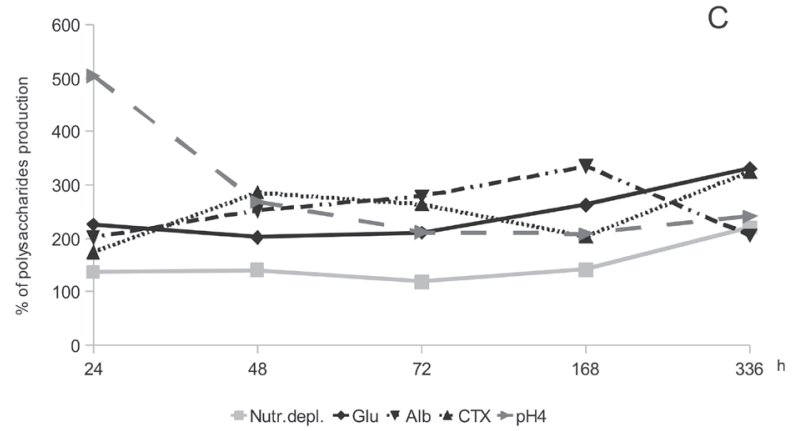

B

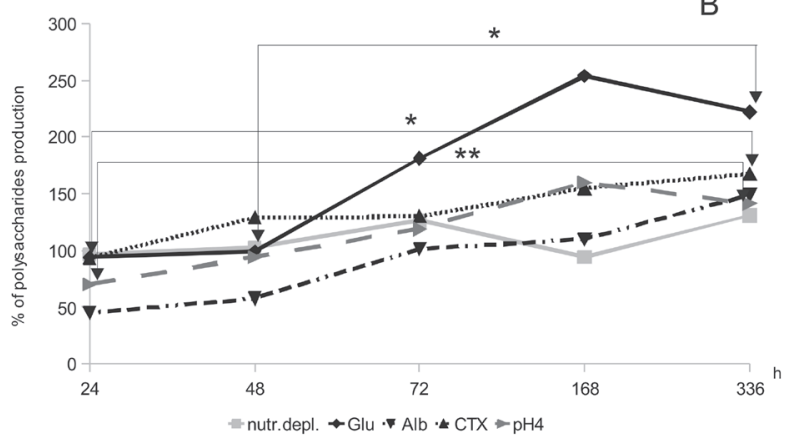

Figure 2. Comparison of polysaccharides levels after $P$. mirabilis biofilm cultivation with the addition of various factors (\% of polysaccharides production in relation to the control medium), obtained using three studied methods: A - ELLA-WGA; B - ELLA-HPA; C — phenol-sulphuric acid.

*values statistically significant at $p \leq 0.05 ;{ }^{* *}$ values highly statistically significant at $p \leq 0.01$.

\section{CLSM analysis}

The results obtained by the colorimetric methods were confirmed by biofilm analysis in a confocal laser scanning microscope. They are presented for two selected strains, after $48 \mathrm{~h}$ cultivation in media supplemented with tested factors. The bacterial cells and the polysaccharide layers were visualized and the levels of fluorescence: green emitted by bacterial cells (SYTO 13) and red emited by WGA-TRITC were compared. The ratios between those signals were counted and they are presented in Table 2, as percentage values calculated in relation to control conditions. The overproduction of polysacharides (the red fluorescence dominated) was determined in all cases but sometimes on very low levels (albumin - P. mirabilis 70 - about $111 \%$ ). The overproduction of $\mathrm{N}$-acetyloglucosamine varied between $422-587 \%$ for P. mirabilis 41 and $111-1134 \%$ for P. mirabilis 70 .

Figure 3 presents samples of images where red fluorescence (WGA-TRITC) and green fluorescence (SYTO 13) are merged. P. mirabilis biofilm cultivated under optimal conditions (Fig. 3A, C) was characterized by a small amount of EPS - a balance between the red and the green signals was observed. After merging of images obtained after biofilms cultivation in media supplemented with a high concentration of glucose, the EPS overproduction was revealed and the red fluorescence dominated (Fig. 3B, D). At the same time, additional images were made, which allowed assessing the biofilm structure and thickness (images not shown). After cultivation in optimal condition the biofilm was well organized and its thickness was about $16.1 \pm 1.8 \mathrm{~mm}$. The biofilm thickness in media supplemented with glucose reached about $22.3 \pm 3.1 \mathrm{~mm}$.
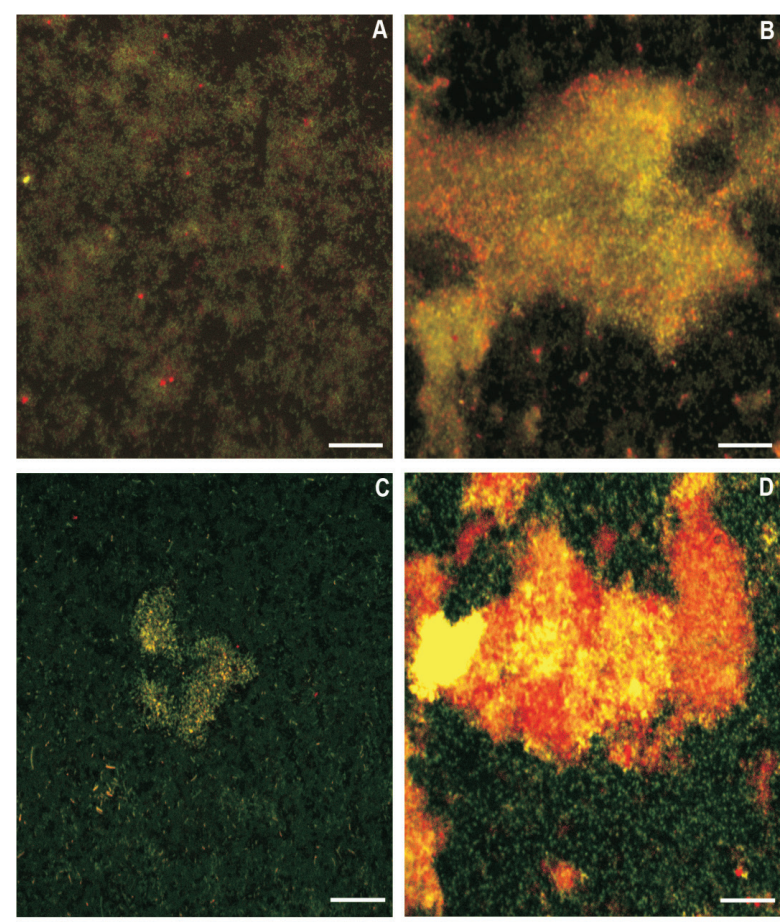

Figure 3. Fluorescence microscopy analysis of $P$. mirabilis biofilm (dual staining: SYTO 13 and WGA-TRITC).

(A) P. mirabilis 41 biofilm, after cultivation in optimal conditions, (B); P. mirabilis 41 biofilm, after cultivation in media supplemented with glucose, (C) P. mirabilis 70 biofilm, after cultivation in optimal conditions, (D) P. mirabilis 70 biofilm, after cultivation in media supplemented with glucose. 


\section{DISCUSSION}

$P$. mirabilis is the main cause of urinary tract infections in patients with urinary catheters (Jacobsen et al., 2008, Stankowska et al., 2012). These bacteria form an extremely durable biofilm, which is very difficult to eradicate, mainly due to the resistance (in high concentrations) of sessile bacteria to most of recommended antibiotics. In our previous studies we confirmed the high resistance of P. mirabilis biofilms to most antibiotics (Moryl et al., 2013). Biofilms are also resistant to many chemical and physical factors, disinfectants and immune system agents. Therefore, it is essential to examine the structure and properties of biofilm. The matrix that surrounds the bacterial cells in biofilm plays a crucial role in sessile bacteria resistance to antibiotics (Flemming et al., 2008). Extracellular polymers are also involved in cells adhesion to a solid surface and in the formation of a three-dimensional structure of biofilm (Wingender et al., 1999). In the future identification of matrix components may allow easier elimination of biofilm from abiotic surfaces.

The aim of the study was the analysis of differences in the levels of polysaccharides in P. mirabilis biofilms after cultivation in optimal and stress conditions. It is necessary to identify factor, which might delay or even prevent matrix formation. We investigated nutrient and stress conditions, that could influence the matrix quantity. Different factors affecting biofilm formation (data not shown) were chosen for the study, e.g. albumin at a concentration of $1.54 \mathrm{mg} / \mathrm{ml}$, which corresponds to albuminuria observed in the urine of patients with kidneys disorders (nephritic syndrome) or cefotaxime (CTX) at a subinhibitory concentration of $32 \mathrm{mg} / \mathrm{ml}$. In the previous studies the sensitivity of $P$. mirabilis to recommended antibiotics had been determined. Most of $P$. mirabilis strains in planktonic forms were susceptible to cephalosporins, but in biofilms they occurred to be resistant (Moryl et al., 2013).

Polysaccharides levels in biofilms were determined using different techniques. The well known methods by Dubois et al. (1956) and Lowry et al. (1951) were applied to study the ratio of the quantity of proteins to polysaccharides in biofilm. The phenol-sulphuric acid colorimetric method allows investigating the total saccharides concentration - neutral sugars in oligosacharides, proteoglycans, glycoproteins and glycolipids. This commonly used 96-well microplate method is very reliable, and requires only 1-150 nM of polysaccharides per well for accurate analysis (Masuko et al., 2005). The well known enzyme linked lectinosorbent assay (ELLA) using lectins, which recognize glicoproteins residues most frequently observed in biofilm matrices, was useful for characterization and quantification of selected sugars in biofilm (Leriche et al., 2000). Two lectins: wheat germ agglutinin (WGA), which binds N-acetyl-D-glucosamine and/or N-acetylneuraminic acid (sialic acid) and Helix pomatia aglutinin (HPA) binding $\mathrm{N}$-acetylogalactosamine were used. The CLSM technique was used for quantification of several biofilm parameters, e.g.: biofilm density and distribution on the surface. CLSM combined with fluorescent lectins is a method of choice for the in situ investigation of biofilm matrix components - it allows the analysis of composition and structural chemistry of biofilms (Lal et al., 2010).

The environmental signals had a different influence on bacterial biofilm growth and matrix synthesis. Some bacteria exist as sessile forms only in rich environments, e.g. EPS production by Cronobacter sakazakii is enhanced after biofilm cultivation in TSB (Jung et al., 2013). Other species better form biofilms in adverse conditions. For example, in the case of Piscirickettsia salmonis nutrient limitation induces stress, which leads to bacterial cells aggregation, stronger biofilm formation and production of large amounts of polysaccharides (Marshall et al., 2012). The same effect was observed after $P$. mirabilis biofilm cultivation in medium containing a tenfold lower amount of nutrients. An about fourfold increase (compared to optimal conditions) in total polysaccharides levels was observed. Zalewska-Piatek et al. (2013) studied the effects of nutrient and stress factors on the process of Escherichia coli biofilm formation. They revealed that nutritional suplementation with glucose, glucose with iron salts or casamino acids supported biofilm formation by E. coli strains. Similar results were obtained by Jung et al. (2013), who confirmed that the addition of glucose or sucrose to culture medium stimulated EPS synthesis and biofilm growth of C. sakazakii. A high concentration of glucose in growth medium resulted in an increase in polysaccharide levels in $P$. mirabilis biofilms in all cultivation times (24-336 h). We noticed an about fourfold increse in total carbohydrate levels for $80 \%$ strains and an about twofold increase in glycoproteins levels for $70 \%$ strains. Petry et al. (2000) also observed a high level of extracellular polysaccharides after the cultivation of Lactobacillus delbrueckii in media containing $10 \mathrm{mg} / \mathrm{ml}$ of glucose. The most EPS were produced at the end of growth - in the stationary phase. It suggests that glucose (in the late stationary phase) is used for EPS production. It is well known that the $\mathrm{pH}$ of the environment has a huge impact on the growth of bacteria. It influences, e.g. enzyme activity, cell membrane morphology and affects nutrient solubility and its uptake by microorganisms (Bajaj et al., 2009). Most bacteria exhibit the highest growth rate at optimal pH. Razack et al. (2013) demonstrated that the maximum productivity of EPS by Bacillus subtilis occurred at $35^{\circ} \mathrm{C}$ and $\mathrm{pH}$ 7. Similar observations were made by Lee et al. (1997) and Petry et al. (2000), who determined the optimal conditions for the synthesis of EPS by Bacillus polymyxa and L. delbrueckiv, respectively. For B. polymyxa the highest yield of exopolysaccharides was observed at $\mathrm{pH} 7-8$ in sucrose containing medium and a relatively low concentration of EPS was obtained when $\mathrm{pH}$ was 4.5 . Growth of $L$. delbrueckii in $\mathrm{pH}$-controlled ( $\mathrm{pH}$ 6) medium resulted in a 3-4 times higher yield of EPS than that obtained under non-pH-regulated conditions. All these studies confirmed the observation that lowering of culture medium $\mathrm{pH}$ leads to a reduction in bacterial growth and the synthesis of extracellular polysaccharides. In contrast to the above-described results, Jung et al. (2013) did not observe a reduction in polysaccharides synthesis with decreasing environmental $\mathrm{pH}$ (to $\mathrm{pH}$ 5) in tested C. sakaqakii strains but, interestingly, found a significant decrease in the nuber of microorganisms cells. In our studies we confirmed that acidic $\mathrm{pH}$ (4) strongly affected the bacterial population (data not shown), but the amounts of polysaccharides were higher compared to those obtained in optimal conditions (pH 7).

We also found (using all tested methods) that subinhibitory doses of cefotaxime stimulated Proteus bacteria $(80 \%$ of tested strains) to greater synthesis of polysaccharides. This phenomenon could confirm the protective role of EPS in the biofilm structure, which in stress conditions is necessary for bacterial survival. On the other hand, many studies concerning the influence of drugs on sessile bacteria growth revealed that subminimal doses of antibiotics inhibited bacteria adhesion and biofilm formation processes. It is probable that chemio- 
therapeutic agents have an effect on bacterial molecules (e.g. fimbriae) expressed on the bacterial surface, which consequently leads to changes in bacterial cell surface hydrophobicity (Balague et al., 2011). However, those agents could also influence the EPS layer, e.g. reduce the amount of matrix. Wojnicz et al. (2007) found that ciprofloxacin and amikacin decreased the number of E. coli strains which had a polysaccharide capsule.

An important role of cephalosporins in the reduction of EPS was also demonstrated (La Tourette Prosser et al., 1997, Balague et al., 2011). Due to the fact that antibiotics have been observed to influence the synthesis of biofilm matrix of different bacteria species in variety of ways, it is very important to be wary of antibiotic therapy implementation.

The application of CLSM combined with fluorescent lectins allowed us to reveal extracellular glycoconjugates distribution in an intact biofilm. Both ELLA and CLSM confirmed that $P$. mirabilis matrix contained different amino sugars like: $\mathrm{N}$-acetylglucosamine and $\mathrm{N}$-acetylgalactoseamine as well as sialic acids. The results obtained by the colorimetric methods have been fully confirmed by CLSM photographs.

Lectins which have the ability to bind to specific glycoproteins, are frequently used to visualize these compounds in EPS. Zippel \& Neu (2011) used a large panel of lectins (70) to investigate distribution of EPS glycoconjugates in tufa-associated biofilm. They detected the binding of 40 lectins to biofilm and confirmed the presence of neutral sugars e.g. fucose, galactose, amino sugars and sialic acids in the biofilm matrix. Lal et al. (2010) also demonstrated that CLSM coupled with fluorescent stains could be a successful tool for the study of the Candida albicans matrix (extracellular material containing glucose and mannose residues). Bridier et al. (2013) also observed a highly regular cells organization in $B$. subtilis biofilm, with cells connected by EPS material, composed partly of $\mathrm{N}$-acetylglucosamine residues.

The presented study provides background information essential for our future studies on the analysis of the matrix composition and proper characterisation of sugars in $P$. mirabilis biofilms. The obtained results show that the culture medium and environmental conditions play a crucial role in the biofilm structure formation, which should always be taken into consideration in the treatment of infections caused by these microorganisms.

\section{REFERENCES}

Bajaj IB, Lele SS, Singhal RS (2009) A statistical approach to optimization of fermentative production of poly (gamma glutamic acid) from Bacillus licheniformis NCIM 2324. Biores Tech 100: 826-832.

Balague C, Perez J, Rinaudo M, Fernandez L (2011) Inhibition of the adhesion to catheters of uropathogenic Escherichia coli by sub-inhibitory concentrations of cefotaxime. Eur J Obstet Gynecol Reprod Biol 155: 150-156.

Bridier A, Meylheuc T, Briandet R (2013) Realistic representation of Bacillus subtilis biofilms architecture using combined microscopy (CLSM, ESEM and FESEM). Micron 48: 65-69.

Czaczyk K, Myszka K (2007) Biosynthesis of extracellular polymeric substances (EPS) and its role in microbial biofilm formation. Polish J Environ Stud 16: 799-806.

Dubois M, Gilles K, Hamilton J, Rebers P, Smith F (1956) Colorimetric method for determination of sugars and related substances. Anal Chem 28: 350-356.

Fleming HC, Neu T, Wozniak D (2007) The EPS matrix: the house of biofilm cells. J Bacteriol 189: 7945-7947.
Jacobsen S, Stickler DJ, Mobley HI, Shirtliff MF (2008) Complicated catheter associated UTI due to Escherichia coli and Proteus mirabilis. Clin Microb Rev 21: 26-57.

Jung JH, Choi NY, Lee SY (2013) Biofilm formation and exopolysaccharide (EPS) production by Cronobacter sakazakii depending on environmental conditions. Food Microbiology 34: 70-80.

La Tourette Prosser B, Taylor D, Dix BA, Cleeland R (1997) Methods for evaluating effects of antibiotics on bacterial biofilms. Antimicrob Ag Chem 31: 1502-1506.

Lal P, Sharma D, Pruthi P, Pruthi V (2010) Exopolisaccharide analysis of biofilm-forming Candida albicans. Appl Microbiol 109: 128-136.

Lee IY, Seo WT, Kim G J, Kim MK, Ahn SG, Kwon GS, Park YH (1997) Optimization of fermentation conditions for production of exopolysaccharide from Bacillus polymyxa. Bioproc Eng 16: 71-75.

Lee WY, Park Y, Ahn JK, Ka KH, Park SY (2007) Factors influencing the production of endopolysacharide and exopolysaccharide from Genoderma appapplanatum. Enz Mic Tech 40: 249-254.

Leriche V, Sibille P, Carpentier B (2000) Use of enzyme-linked lectinosorbent assay to monitor the shift in polysaccharide composition in bacteria biofilms. Appl Environ Microb 66: 1851-1856.

Lowry O, Rosenbrough N, Lewis - Farr A. Randall R (1951) Protein measurement with the Folin phenol reagent. J Biol Chem 193: 265275.

Marshall SH, Gomez FA, Ramirez R, Nilo L, Henriquez V (2012) Biofilm generation by Piscirickettsia salmonis under growth stress conditions: a putative in vivo survival/persistence strategy in marine environments. Res Microbiol 163: 557-566.

Masuko T, Minami A, Iwasaki N, Majima T, Nishimura SI, Lee YC (2005) Carbohydrate analysis by a phenol-sulphuric acid method in microplate format. Anal Bioch 339: 69-72.

Moryl M, Torzewska A, Jałmużna P, Różalski A (2013) Analysis of Proteus mirabilis distribution in multi-species biofilms on urinary catheters and determination of bacteria resistance to antimicrobial agents. Pol J Microbiol 62: 377-384.

Muzzi-Bjornson L, Macera L (2011) Preventing infection in elders with long-term indwelling urinary catheters. I Am Acad Nurse Prac 23: $127-134$.

Nwodo UU, Green E, Okoh AI (2012) Bacterial exopolysaccharides: functionality and prospects. Int J Mol Sci 13: 14002-14015.

Petry S, Furlan S, Crepeau M, Cerning J, Desmazeaudf M (2000) Factors affecting exocellular polysaccharide production by Lactobacillus delbrueckii subsp. bulgaricus grown in a chemically defined medium. Appl Environ Microbiol 66: 3427-3431.

Razack SA, Velayutham V, Thangavelu V (2013) Influence of various parameters on exopolysaccharide production from Bacillus subtilis. Int J Chem Tech Res 5: 2221-2228.

Różalski A, Kwil I, Torzewska A, Baranowska M, Stączek P (2007) Bakterie z rodzaju Proteus - cechy i czynniki chorobotwórczości. Post Hig Med Dosw 61: 204-219 (in Polish).

Stankowska D, Czerwonka G, Rozalska S, Grosicka M, Dziadek J, Kaca W (2012) Influence of quorum sensing signal molecules on biofilm formation in Proteus mirabilis O18. Folia Microbiol 57: 53-60.

Starkey M, Gray K, Chang S, Parsek M (2004) A sticky business: the extracellular polymeric substance matrix of bacterial biofilms. In $\mathrm{Mi}$ crobial biofilms. Ghannoum G, O’Toole G, eds, pp 174-192. ASM Press, Washington DC.

Stickler DJ, Feneley RCL (2011) The encrustation and blockage of long-term indwelling bladder catheters: a way forward in prevention and control. Spinal Cord 48: 784-790.

Sutherland I (2001) Biofilm exopolysaccharides: a strong and sticky framework. Microbiol 147: 3-9.

Vu B, Chen M, Crawford R, Ivanova EP (2009) Bacterial extracellular polysaccharides involved in biofilm formation. Molecules 14: 25352554 .

Wingender I, Neu TR, Flemming HC (1999) What are bacterial extracellular polymeric substances? In Microbial extracellular polymeric substances. Wingender I, Neu TR, Flemming HC, eds, pp 1-15. Springer-Verlag Berlin Heidelberg.

Wojnicz D, Tichaczek-Goska D, Cisowska A (2010) Effect of subinhibitory concentrations of amikacin and ciprofloxacin on the K1 antigen expression and phagocytosis of Escherichia coli strains. Adv Clin Exp Med 19: 429-436.

Zalewska-Piątek B, Wilkanowicz S, Bruździak P, Piatek R, Kur J (2013) Biochemical characteristic of biofilm of uropathogenic Escherichia coli Dr+ strains. Microbiol Res 168: 367-378.

Zippel B, Neu TR (2011) Characterization of glycoconjugates of extracellular polymeric substances in tufa-associated biofilms by using fluorescence lectin-binding analysis. Appl Environ Microbiol 77: 505516. 